\title{
Reasons for Success in Competitive Swimming among Various Human Races
}

\author{
Mr. Partha Pratim Majumder ${ }^{1}$, Dr. Sayantani Roy Choudhury ${ }^{2}$ \\ 1. Director, Swimming, Indian life saving society, CSC, Saturday Club, Kolkata, India \\ 2. Associate Professor, Unitedworld School of Business, Kolkata, India
}

\begin{abstract}
It is very interesting to learn that though some consider swimming as Athletic Sports but when we consider the best sportspersons in swimming and running, there is a totally different result in terms of Human Race. It made us interested to find out the reason, why Swimming is not dominated by the Black race, what physical disadvantages they have in swimming. Also what physical advantages an Asian have in comparison with Dravidian to lead the Swimming World after White race! As we have analysed physical factors, there are some prominent structural difference in between 'black' and 'white' races which clarifies why White people are good in swimming. But these cannot reflect a clear difference in performance between Chinese and Dravidian. The question remains, what might be the determined factors behind the performance of a swimmer! The other factors can be (a) socio-cultural factor, (b) financial factor and most importantly (c) technical factor. We do differentiate between 'blacks' and 'white' swimmers in that line of arguments. But if we again come to compare between Chinese and Dravidians swimmers, it is difficult to get support from data in this context. Thus there should be another important factor by which we can explain the missing link. That may be the factor by which a swimmer can overcome his or her physical, socio-cultural as well as financial draw-backs. That factor may reveal the reason behind the success of Chinese swimmers in recent past. This factor may point out the reason behind absence of Dravidians in international swimming though they are very close to Chinese in terms of other factors. That missing link is identified as 'technical factor'. Despite having adverse physical factor upto certain extend, it can be overcome by Systematic Training Pattern, Proper Filtration of Talent with Social recognition and Financial Support.
\end{abstract}

Keywords: Competitive swimming, Socio-cultural, techniques, human races, physical.

\section{Introduction}

Competitive Swimming has taken a great part to build the Nations Pride, specially when the major sporting event like Olympic is considered. Swimming which has been part of Modern Olympic Games first held in 1896 at Athens. In 1908 the World Swimming Association called Fédération Internationale de Natation (FINA), was formed. [Lisa Porter, 2010]

This sport contributes the $2^{\text {nd }}$ large numbers of medals in the Medal tally (after Athletics). Let us analyse few factors that involve competitive swimming in terms of various human races.

The different type humans races are as follows:-[11]

Australian Aborigines and Papuans

American Indians (Native Americans)

Pacific Islanders

Blacks (Sub-Saharan Africans)

Whites (Caucasians)

Dravidians (Indians)

Asians

Mixed Race Population.

Table 1: Composition of world population

\begin{tabular}{|l|l|l|}
\hline Composition of World Populations & Per Cent & Geographic Origin \\
\hline Race & 10.5 & Sub-Saharan Africa \\
\hline Negroid or Black & 19 & Europe, Near East, North Africa \\
\hline Caucasians or Whites & 12 & India \\
\hline Dravidians & 48 & Asia \\
\hline Asians or Mongolian's & 10.5 & Various \\
\hline $\begin{array}{l}\text { Mixed Race, Aborigine, American Indian, } \\
\text { Pacific Islanders etc. }\end{array}$ & 10.5 \\
\hline
\end{tabular}


As we can see there are, four Major Human Race in the World Population and Balance is Mixed and other human races. When we consider the performance in terms of some major Swimming and Running events, the results of last four Olympics are as Follows in term of the above four human races (or if it mixed the Dominant race):-[14]

TABLE 2: Comparison through Olympic results

\begin{tabular}{|c|c|c|c|c|c|c|c|c|c|c|c|c|}
\hline \multirow{3}{*}{$\begin{array}{l}\text { Swimming } \\
\text { Event }\end{array}$} & \multicolumn{3}{|c|}{ Olympic Result 2000} & \multicolumn{3}{|c|}{ Olympic Result 2004} & \multicolumn{3}{|c|}{ Olympic Result 2008} & \multicolumn{3}{|c|}{ Olympic Result 2012} \\
\hline & \multicolumn{3}{|c|}{ With country code } & \multicolumn{3}{|c|}{ With country code } & \multicolumn{3}{|c|}{ With country code } & \multicolumn{3}{|c|}{ With country code } \\
\hline & Gold & Silver & Bronze & Gold & Silver & Bronze & Gold & Silver & Bronze & Gold & Silver & Bronze \\
\hline $\begin{array}{l}50 \mathrm{mt} \text { Freestyle } \\
\text { (Men) }\end{array}$ & USA & USA & NED & USA & CRO & RSA & BRA & FRA & FRA & FRA & USA & BRA \\
\hline $\begin{array}{l}\text { 400mt } \\
\text { Freestyle(Men) }\end{array}$ & AUS & ITA & USA & AUS & AUS & USA & KOR & CHI & USA & CHI & KOR & USA \\
\hline $\begin{array}{l}\text { 100mt Back } \\
\text { Stroke (Men) }\end{array}$ & USA & AUS & GER & USA & AUT & JPN & USA & USA & AUS & USA & USA & JPN \\
\hline $\begin{array}{l}\text { 100mt } \\
\text { Butterfly(Men) }\end{array}$ & SWE & AUS & AUS & USA & USA & URK & USA & SRB & AUS & USA & RUS & RSA \\
\hline $\begin{array}{l}\text { 100mt Breast } \\
\text { Stroke(Men) }\end{array}$ & ITA & USA & RUS & JPN & USA & FRA & RUS & AUS & USA & JPN & NOR & FRA \\
\hline $\begin{array}{l}\text { 50mt (Women) } \\
\text { Freestyle }\end{array}$ & NED & SWE & USA & NED & FRA & AUS & GER & USA & AUS & NED & BLR & NED \\
\hline $\begin{array}{l}\text { 400mt Freestyle } \\
\text { (Women) }\end{array}$ & USA & USA & CRC & FRA & POL & USA & GBR & USA & GBR & FRA & USA & GBR \\
\hline $\begin{array}{l}\text { 100Back Stroke } \\
\text { (Women) }\end{array}$ & ROM & JPN & SPN & USA & ZIM & FRA & USA & ZIM & USA & USA & AUS & JPN \\
\hline $\begin{array}{l}100 \text { Butterfly } \\
\text { (Women) }\end{array}$ & NED & SVK & USA & AUS & POL & NED & AUS & USA & AUS & USA & CHN & AUS \\
\hline $\begin{array}{l}\text { 100mt Breast } \\
\text { Stroke(Women) }\end{array}$ & USA & AUS & RSA & CHI & AUS & AUS & AUS & USA & AUT & LUT & USA & JPN \\
\hline $\begin{array}{l}\text { ALTHLETIC } \\
\text { EVENTS }\end{array}$ & & & & & & & & & & & & \\
\hline $\begin{array}{l}\text { 100mt } \\
\text { RUN[MEN] }\end{array}$ & USA & TRI & BAR & USA & POR & USA & JAM & TTO & USA & JAM & JAM & USA \\
\hline $\begin{array}{l}\text { 10000M } \\
\text { RUN[MEN] }\end{array}$ & ETH & KEN & ETH & ETH & ETH & ERI & ETH & ETH & KEN & GBR & USA & ETH \\
\hline $\begin{array}{l}\text { 100M } \\
\text { RUN[WOMEN] }\end{array}$ & GRE & JAM & JAM & BLR & USA & JAM & JAM & JAM & JAM & JAM & USA & JAM \\
\hline $\begin{array}{l}\text { 10000M } \\
\text { RUN[WOMEN] }\end{array}$ & ETH & ETH & GRE & CHI & ETH & ETH & ETH & TUR & USA & ETH & KEN & KEN \\
\hline
\end{tabular}

Table -2 : Colour code:

Caucasian or White Race : white colour

Mongolian or Asian Race: yellow colour

Negroid or Black Race : Grey colour

Dravidian : N.A.

Note : This colour doesn't ensure of the Pure or Mixed race, but it indicate the dominant race of the participating sportspersons.]

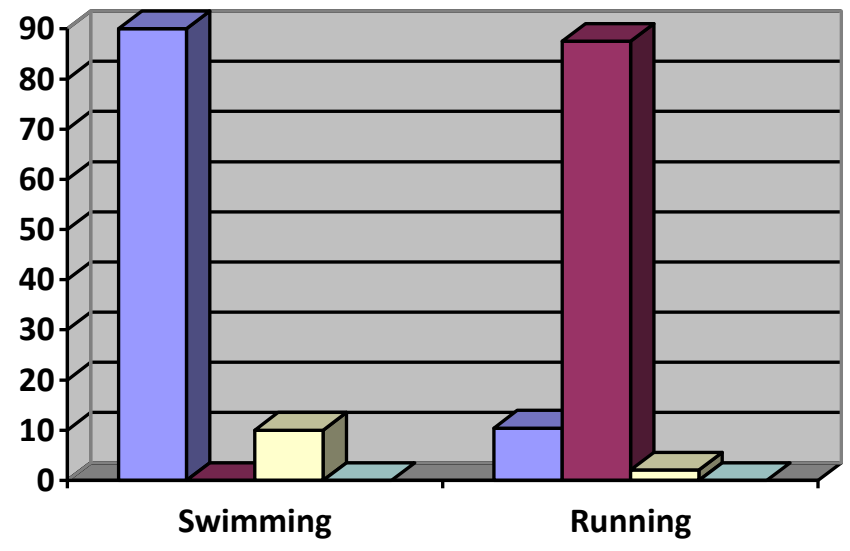

\begin{tabular}{|l|}
$\square$ White \\
$\square$ Black \\
$\square$ Asian \\
$\square$ Dravidian
\end{tabular}

Figure 1: Medal Winning Chart (on \% basis) between Swimming and Running comparing last four Olympic Result, among Different Human Race in reference to TABLE-2 


\subsection{Objective-}

It is very interesting to learn that though some consider swimming as an Athletic Sports but when we consider the best sportspersons in swimming and running, there is a totally different result in terms of Human Race. As we can see from the "Table 2" and "Figure 1", Swimming (both Short and Long Distance and different strokes) is Dominated (Both men and women) by the White (Aryans or Aryans dominant mix) and part being leaded by Asian, the existence of Black or Dravidian race are not in the lead. Whereas the Running (Both Short and Long Distance) is mainly dominated by the Black race and quite few White are there in the league among the top performers.

It made us interested to find out the reason, why Swimming is not dominated by the Black race, what physical disadvantages they have in swimming and Advantages they have in running. Also what physical advantages an Asian have in comparison with Dravidian to lead the Swimming World after White race.

\subsection{Comparative study of Physical structure of different human race in respect of competitive swimming-} 1.3.1 Floatation Capacity

a) Centre of gravity and centre of buoyancy are behind swimming capabilities. Adrian Bejan (2010), a professor of mechanical engineering at Duke University in North Carolina, and Dr Edward Jones (2010) of Howard University in Washington discussed in The Daily Telegraph that mass that falls from a higher altitude falls faster. In running, the altitude is set by the location of the center of gravity. For the fastest swimmers, longer torsos allow the body to fall forward farther, riding the larger and faster wave. The

researchers concluded that, on

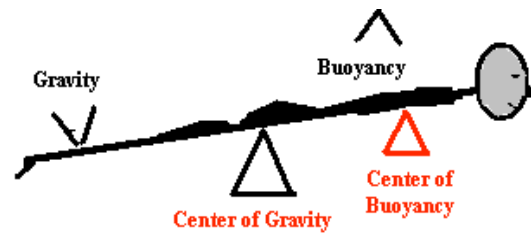

average, blacks have about a 3\% higher center of gravity than whites. That may make black sprinters 1.5 percent faster than white sprinters. Using that formula, whites may have a similar advantage over blacks in swimming [Mathu Moore, 2010]. The paper also reported that although Asians have lower centers of mass/longer relative torsos like whites, European whites have an advantage in swimming due to longer overall torsos (Adrian Bejan; Edward C. Jones; Jordan D. Charles; 2010).

b) Racial differences could come through the structure of bone. Asian Indians are lean "sinkers" because they have little fat and a high percentage of bone and muscle in their physical make-up. On the other hand, the Inuit are fat and round, adaptations that minimize heat loss. That combination also makes them float well. Similarly, because blacks have such dense bones, they are less buoyant and less likely to be swimming champions. [William Robertson Boggs, 1992]

c) The volume of air in the lungs has an important effect. After inhalation, a greater amount of water is displaced without any increase in weight. Thus, floating is easier when the lungs and chest are expanded but the angle of float will be increased. But from different study, it is found that there is no significance difference among the races in this respect.(Brent S. Rushall, 2007)

1.3.2 Height . The average height for male swimmers is $187.1 \pm 7.2 \mathrm{~cm}$. It is about $14 \mathrm{~cm}$ higher than in female swimmers. The height in male swimmers is more variable between events than in female swimmers. Tall Swimmers are at an advantage because they have Bigger Feet to Kick with Longer Arms i.e. "Longer Lever" to pull with.

Although if we consider general height among different Human Races, Aryans and Part of Black Race have higher average height compare to Asians \& Dravidians. But we have observed in Modern Swimming the top swimmers have nearly same height despite of different races. This may be because of Proper Screening Process. E.g. Although the average male height of Chinese (1.663 mt. or $5 \mathrm{ft} 5 \frac{1}{2}$ in) is lower than the average height of American (1.789 mt or $5 \mathrm{ft} \mathrm{101/2}$ in) or Australian (1.784 mt or 5ft 10in), but the Top Swimmers from China also have good height. Recent world champion Sun Yang is $1.98 \mathrm{mt}$ (6 ft $6 \mathrm{in})$ tall. However there are exceptions also. The average height for an Olympic Gold Medalist in Men 200 Free Style is $6 \mathrm{ft} 4$ inches over past 12 years (Eugena Jung, 2012), but South Korean swimmer Park Tae Hwan despite having a height of 6 feet only (which is 3.6 inches below the Olympic Average height) won Gold in 400 Free Style in 2008 Olympic and Silver in 2012 Olympic [13].

After the above detailed discussion, it can be stated clearly that though physical structure is an important factor but not the sole factor behind difference in swimming capability. There are some prominent structural difference in between 'black' and 'white' which clarifies why White people are good in swimming compare to Black in swimming, though Black race are better in running; but these cannot reflect a clear 
difference in performance between Chinese and Dravidian. As per body fat, Chinese are same as Dravidian and more surprisingly adipose tissue concentration with Chinese are less than all other race along with the Dravidian (Dale R Wagner and Vivian H Heyward, 2000).

Therefore the question remains, what might be the determined factors behind the performance of a swimmer! Is it only the Physical Factor in different human race?

Let us discuss some other factors:

The other factors can be (a) socio-cultural factor, (b) financial factor and most importantly (c) technical factor.

\subsection{Socio-cultural factors-}

As we have discussed early, swimming is not a sport in which we tend to see black faces. Contrast this with sprinting and basketball, which are dominated by black athletes from all over the world. The 10 fastest $100 \mathrm{~m}$ male sprinters in the world are all black, as are eight of the world's 10 fastest women. There is undoubtedly a wide gap between black and white participation in certain sports. According to a recent study by USA Swimming, nearly $60 \%$ of African-American children between the ages of six and 16 are unable to swim, in comparison to $31 \%$ of white children (Chin MK, So RC, Yuan YW, Li RC, Wong AS, 1994). It shows sociocultural factors are very much influential. Biology alone cannot account for success.

One of the past studies (Lola Adesioye, 2008) of the survey evidently justify the hypothesis that the social status of families from where the swimmers originated is one dimension of inequalities encountered in competitive swimming. This sport is chosen mostly by the children of upper-middle class people in USA.

Different study shows that, children whose parents were of former performers in swimming and children of former elite athletes in other individual sports who are getting engaged with competitive swimming, mostly on the initiative of their parents. This reveals the high degree of self-reproduction of sport society, a tendency which is expected to continue in the future as well (Lola Adesioye, 2008).

\subsection{Financial factors-}

A 1999 study by the University of Arizona actually shows that so ingrained are the stereotypes about racial superiority and inferiority in certain sports that they affect not only which sports both black and white people gravitate toward but also their performance in those sports.

The environment in which we live and are educated also plays a role. Although Eric the Eel was mocked for his slowness, the reality is that in his hometown in Equatorial Guinea, he only had access to a $20 \mathrm{~m}$ pool. (Lola Adesiove, 2008)

In the west, where the vast majority of black people live in the inner cities, the types of sports they engage in are the ones most suited to an inner-city environment, not only in terms of access but also cost. This may explain why basketball courts are found on most inner-city blocks in African-American neighborhoods: they are cheap to build, require little maintenance and participation is affordable.

There are very few swimming pools, tennis courts and golf courses built in black communities, and they tend to require higher financial outlay. Golf and tennis are usually the domain of private membership clubs, and - even with the stunning successes of Tiger Woods and the Williams sisters - are still considered white, upper middleclass sports. The USA Swimming study found that swimming ability, regardless of race, actually increases in relation to parents' income and education.

In the same way, Black Africans have had restricted access to swimming pools that are both be privately or publicly owned. Private swimming pools in residential areas are owned by homeowners and access is determined by the home owner. The majority of home owners with pools are wealthy. Many Black people cannot afford the high costs of building and maintaining an individually owned pool.

It has been shown in the study by Karen D. Berukoff and Grant Michael Hill (2010), 'A Study of Factors That Influence the Swimming Performance of Hispanic High School Students' that swimming opportunity has a very strong significant positive relationship with swimming performance.

The characteristics of the personality which are necessary for competition - independence, assuming risks, longterm planning (to be discussed in Technical Factor), and acceptance of deferred gratification - are precisely overlapping with those elements of the life-style which children and youth growing up in an entrepreneurial culture are socialized in. The financial situation of sport worsened to such an extent that the families of young athletes are necessarily overtaking the financial burden of sporting careers.

A lot of discussion has been done in two earlier paragraphs. We do differentiate between 'blacks' and 'white' swimmers in that line of arguments. But if we again come to compare between Chinese and Dravidians swimmers, it is difficult to get support from data in this context.

Thus there should be another important factor by which we can explain the missing link. That may be the factor by which a swimmer can overcome his or her physical, socio-cultural as well as financial draw-backs. That factor may reveal the reason behind the success of Chinese swimmers in recent past. This factor may point out 
the reason behind absence of Dravidians in international swimming though they are very close to Chinese in terms of other factors.

\subsection{Technical Factor}

Swimming is a Technique Driven Sports. The Performance of a Swimmers not merely dependent on the physical advantage of a Swimmer (Though it is a factor) as we can understand from the study of Olympic result of different human race, but it also depend on few major factors (for which the Swimmers of China and Japan are doing so well despite having less physical advantage then the White Americans, Australians and Europeans). These factors are:-

1. Stroke Technique: Good technique enable a swimmer to pull more water in an efficient manner (that mean without wasting too much of energy per pull/kick) with less Body Drag.

2. Mental Strength: It has been seen that many swimmers despite having less basic physical advantages like height, power etc., outperform the race with great mental determination. Some of the major metal strength requirement is the pain bearing capacity at the lactic pic level, managing race pressure against some tough competitor; learn from loosing, killer instinct.

3. Nutrition: Nutrition and proper food habit with the required supplement are not easy to maintain for a low economic background swimmers.

4. Sacrifice: Any Elite Sportsperson need to sacrifice a lot of small thing in their life for the achievement. Some of this thinks are balancing or time management of their personal and education life, lot of small entertainment factor, other sports.

5. X Factor: It has been seen that in a group of Swimmers of same class of physical advantage and doing same in practice one swimmer is doing better in the Vital Swimming Meet, this type of difference can be treated as the X Factor or Competitive spirit of a Swimmer.

6. Long term planning though a systematic training program: All the technical factors discussed above to be imposed on swimmers through a long term planning and well build systematic training program. Though Dravidian and Asian have similar structure but one of the thing that differentiate Asian performance in swimming compare to Dravidian is the Social recognition of Sports and target setting towards the performance. Let us take an example of Chinese swimming in term of Long Term Planning.

In Barcelona Olympic China got four Gold and five Silver medals in Women section [12], but this did not happen on sudden program rather through a long term planning. This success was in part due to the standards used for selecting swimmers of Olympic potential:

1. Evaluation of growth to future performance: In 1980, all All-Chinese swimmers were surveyed for setting up a Chinese outstanding swimmer's model and they found,

a) There was a significant difference between the Chinese male swimmer's height and the Olympic swimmer's.

b) The strength of the Chinese women and men swimmers was much weaker compared with Olympic swimmers.

2. Evaluation of morphology, fitness, and physiology: Understanding the physiological factor, specifically, importance of height of swimmers in the selection procedure was more specific from the basic stages which encourage the tall swimmers to get better opportunity.

\section{Final selection and training.}

For the Chinese Olympic Swimmers, the coaches increased practice intensity, and improved the swimmer's strength.

In 1980, research showed that practice intensity of the Chinese swimmers was too low.

Altitude training is an effective training method, although there is controversy about the effects of altitude training on subsequent performance at sea level. Since 1985, the Chinese swimmers have been to Kunming (where the altitude is almost the same as the Olympic training centre in Colorado Springs) to do altitude training. Usually, the training lasts three to four months, then swimmers return to sea level about two weeks before championships. Before the Barcelona Olympics, the Chinese swimmers and the Unified team all experienced altitude training. [Jinri Jiang, ]

This clearly indicates how a long term well build planning can overcome the physical drawback.

Whereas no such long term measure has been taken to build the swimmers of South East Asian Countries (who are Dravidian Dominant origin), this clarifies the poor result in Swimming by these country in the said Olympic. 


\subsection{Conclusion -}

We can conclude the entire discussion in the following way,

Efficiency in swimming = A function of (factors come from race, socio-cultural factors, financial factors, technical factors). All the factors are very important. A champion swimmer can be a combination of all the above factors.

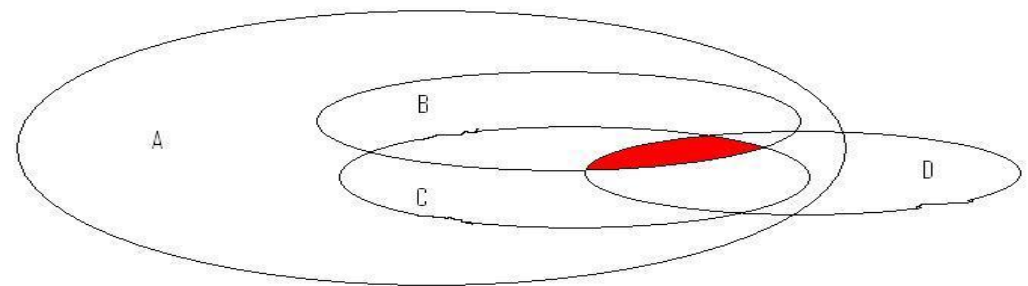

Fig 5: Venn diagram showing four factors and common portion

Above figure can be a good representative of our discussion. We have identified four influencing factors on which performance of a swimmer depends. Suppose 'A' is the factors from race, 'B' is the socio-cultural factors, ' $\mathrm{C}$ ' is the financial factor and ' $\mathrm{D}$ ' is the technical factor. In the diagram, ' $\mathrm{B}$ ' and ' $\mathrm{C}$ ' are shown as a part of ' $\mathrm{A}$ '. Because 'socio-economic' and 'financial' factors can come from different race. A good swimmer may be a combination of all four. In the diagram, 'red' portion represents the common zone. Thus, if a swimmer lies in the 'red' zone, he got all positive influences from all four factors, and could be a champion.

But, there is a very high chance that most of the swimmers stand outside that zone. Somebody can have one, two or three positive factors; may not have all four. Question arises, how to overcome the absence of positive impact of some factors?

A swimmer can never change his or her race. Similarly, it is almost impossible to change his/her socio-cultural factors. One can try to change his/her financial condition, but according to our discussion total economic financial condition should be changed to find some positive influence on the performance of a swimmer. That is a long term phenomenon, beyond the capacity of an individual. So, we are left with the sole factor, that is, technical factor. The performance of a swimmer can definitely be changed with improved technique. Negativity of all other factors can definitely be reduced by proper technique. Therefore, 'B' can lift a swimmer out of all negative impacts of his/her race; it can bring him/her out of ' $\mathrm{A}$ '.

\subsection{Recommendations -}

In the above discussion and study it has been understood that the performance of swimmer in terms of different Human Race are dependent not only on the Physical Factor of each Race but also on the (a) sociocultural factor, (b) financial factor and most importantly (c) technical factor. Despite having Adverse Physical Factor upto a certain extend can be overcome by Systematic Training Pattern, Proper Filtration of Talent with Social recognition and Financial Support. We strongly believe that in Near Future we can see some of the Quality Swimmers will come from Dravidian and Black Race also if the above stated factor supports this sport.

\section{References:}

[1]. Adrian Bejan, Edward C Jones, Jordon D Charles, 2010. The Evolution Of Speed In Athletics: Why The Fastest Runners Are Black And Swimmers White.International Journal of Design and Nature and Ecodynamics. 5(3):199-211.

[2]. Brent S. Rushall. 2007. Floating In Swimming: The Forgotten Technique Modifier. Swimming Science Bulletin, Number 36.

[3]. Chin MK, So RC, Yuan YW, Li RC, Wong AS. 1994. Cardiorespiratory fitness and isokinetic muscle strength of elite Asian junior soccer players. J Sports Med Phys Fitness. 1994 Sep; 34(3):250-7.

[4]. Dale R Wagner and Vivian H Heyward (2000). Measures of body composition in blacks and whites: a comparative review1'2, Am J Clin Nutr, June 2000 vol. 71 no. 6 1392-1402.

[5]. Eugena Jung (2012). Swimmer Overcome Height Challenges, Yale Baily News , 11/09/12

[6]. Jinri Jiang, M.S. How to select potential Olympic swimmers. www.geocities.ws/ddstcoach/Coach.htm

[7]. Karen D. Berukoff and Grant Michael Hill, 2010. A Study of Factors That Influence the Swimming Performance of Hispanic High School Students. International Journal of Aquatic Research and Education,2010, 4, 409-421

[8]. Lisa Porter, 2010.The History of Competitive Swimming. Livestrong.com (http://www.livestrong.com/article/342427-the-history-ofcompetitive-swimming/). 
[9]. Lola Adesioye, 2008. Is race a factor in sports success? The lack of African-American swimmers at the Olympics doesn't mean race determines athletic prowess. theguardian.com, Monday 25 August 2008 09.30 BST.

[10]. Mathu Moore, 2010. Centre of gravity theory for dominance of black sprinters and white swimmers. The Daily Telegraph, 12 Jul 2010

[11]. Scott A Lear, Karin H Humphries, Simi Kohli, Arun Chockalingam, Jiri J Frohlich, and C Laird Birmingham (2007) .Visceral adipose tissue accumulation differs according to ethnic background: results of the Multicultural Community Health Assessment Trial (M-CHAT)1_3. Am J Clin Nutr 2007;86:353-9. Printed in USA. (C) 2007 American Society for Nutrition.

[12]. William Robertson Boggs, 1992. Race and Physical Difference. American Renaissance Magazine, Vol.3, No.12.

[13]. http://www.internetlooks.com/humandifferentiation.html

[14]. www.olympic.org

[15]. http://www.usaswimming.org/DesktopDefault.aspx?TabId=1450\&Alias=Rainbow\&Lang=en

[16]. http://websearch.cs.com/cs/boomframe.jsp

[17]. http://en.wikipedia.org/wiki/Human_height 